Research Article

\title{
Soil Drought and Vegetation Response during 2001-2015 in North China Based on GLDAS and MODIS Data
}

\author{
Siyao Yang, ${ }^{1,2,3,4}$ Dan Meng $\mathbb{D D}^{1,2,3,4}$ Huili Gong, ${ }^{1,2,3,4}$ Xiaojuan Li, ${ }^{1,2,3,4}$ and Xinling Wu $\mathbf{u}^{1,2,3,4}$ \\ ${ }^{1}$ College of Resources Environment and Tourism, Capital Normal University, Beijing 100048, China \\ ${ }^{2}$ Urban Environmental Processes and Digital Modeling Laboratory, Beijing 100048, China \\ ${ }^{3}$ Beijing Laboratory of Water Resource Security, Beijing 100048, China \\ ${ }^{4}$ Beijing Municipal Key Laboratory of Resources Environment and GIS, Beijing 100048, China \\ Correspondence should be addressed to Dan Meng; mengdan@cnu.edu.cn
}

Received 1 February 2018; Accepted 10 April 2018; Published 26 April 2018

Academic Editor: Runping Shen

Copyright ( $\odot 2018$ Siyao Yang et al. This is an open access article distributed under the Creative Commons Attribution License, which permits unrestricted use, distribution, and reproduction in any medium, provided the original work is properly cited.

\begin{abstract}
Drought is a natural disaster caused by long-term water deficit. Because the growth of crops and vegetation is closely related to soil moisture environment, it is of great significance to study the soil drought and vegetation response. In this paper, the soil moisture availability index (SMAI) was developed for quantifying soil drought conditions. The effectiveness and the ability of SMAI to recognize drought events were analyzed, while the vegetation condition index (VCI) was used to characterize the vegetation status. Temporal and spatial variations of soil drought and vegetation condition as well as the impacts of drought on vegetation in North China during 2001-2015 were comprehensively examined. We firstly concluded that SMAI related well with standardized precipitation evapotranspiration index (SPEI), and drought events can be detected by SMAI. Next, the mean value of SMAI in North China showed a decreasing trend in recent 15 years. Finally, the SMAI positively correlated with VCI in most areas of North China, and the response of four types of vegetation to SMAI differed over time. The results of SMAI on vegetation would assist drought research and application in North China.
\end{abstract}

\section{Introduction}

Drought is a natural phenomenon caused by imbalance in water budget, thus leading to water shortage, a sharp drop in groundwater reserves, crop reduction, and other issues. Unlike other forms of natural disasters, droughts often develop slowly and its effect varies from region to region. In the background of global warming, evaporation is getting more intense, so drought is usually becoming more and more serious. The area and severity of drought-affected regions have increased in recent years in China $[1,2]$, especially in the northern China where water resources are relatively scarce. Drought is a long and sustained process; the impact of the initial drought is not obvious, but with the increase of the drought duration, it will cause a series of problems. Vegetation is an important component of land surface coverage, and the response of vegetation to climate change is an important part of global or regional change research issue. Vegetation is the indicator of an ecological environment, including the feedback of drought. Therefore, the study of regional drought and vegetation response is helpful to understand the evolution and regularity of drought and the impact on terrestrial ecological environment, which can provide a reference for the monitoring and evaluation of the regional ecological environment.

$\mathrm{Su}$ et al. have summarized drought monitoring and assessment using remote sensing data. Many indices have been proposed for drought assessment, and each of these indices addresses a specific aspect of drought, including meteorological, soil moisture, hydrological, and socioeconomic drought [3]. The selection of drought indicators is crucial to drought evaluation, while the lack of precipitation and the high temperature are often the beginning of meteorological drought. Therefore, the previous studies of drought are mostly based on the precipitation from the meteorological perspective, mainly by the $Z$-index of available rainfall [4], standardized precipitation index (SPI) 
[5], palmer drought severity index (PDSI) [6], and standardized precipitation evapotranspiration index (SPEI) [7]. The correlation between vegetation parameters and meteorological parameters (such as precipitation and temperature) has been studied [8-10], as well as the response of vegetation to the meteorological drought index $[11,12]$. As the reflection of precipitation and evapotranspiration, soil moisture deficit is a comprehensive feedback of meteorological drought in a certain period of time $[13,14]$. Furthermore, the growth status of vegetation is closely related to the soil water; therefore, it is also necessary to analyze the response of vegetation to soil drought conditions. Considering the seasonal and cumulative effects of drought, the soil moisture deficit index (SMDI) [15] is chosen as the evaluation index of drought.

With the characteristics of the complex and diverse land surface belonging to semihumid areas, North China is sensitive to global climate changes [14]. The seasonal variation of vegetation is significant and especially susceptible to drought conditions because of the low annual precipitation in North China. Considering the impact of drought on vegetation varied in different regions and vegetation types [16], as well as water demand of vegetation differed over seasons [17], it is necessary to study the response of vegetation conditions to soil drought under different conditions from a more detailed spatial and temporal scale [18].

\section{Study Area}

The study area is located in North China $\left(31^{\circ} 23^{\prime}-42^{\circ} 37^{\prime} \mathrm{N}\right.$, $\left.110^{\circ} 15^{\prime}-122^{\circ} 43^{\prime} \mathrm{E}\right)$. It includes the province of Hebei, Henan, Shanxi, and Shandong and the municipalities of Beijing and Tianjin (Figure 1), with an area of $6.929 \times 10^{5} \mathrm{~km}^{2}$. The study area is in the temperate semihumid continental monsoon climate zone. The annual precipitation is between 400 and $800 \mathrm{~mm}$ (decreasing from southeast to northwest), mainly affected by the Pacific monsoon intensity. Due to the precipitation, evaporation and temperature varied greatly at interannual and intraannual timescales, and drought and flood hazards occur mainly in spring and summer, respectively. North China is an important agricultural and livestock breeding base in China. The DEM in Figure 1 shows the terrain of the study area. The northern and western regions of the study area are mountainous, and the main vegetation types are woodland and grassland. While the central and eastern regions are a large area of plain, and the main crops are wheat, corn, peanuts, cotton, and so on.

\section{Data and Methodology}

3.1. Drought Monitoring Index. Soil condition is closely related to agriculture and vegetation status, and soil moisture is often regarded as one of the indices of agricultural drought. SMDI [14] was selected as the drought monitoring index in this study. Because SMDI increases with increasing soil moisture, we renamed it as "soil moisture availability index" (SMAI). The SMAI is calculated as follows:

$$
\begin{aligned}
\mathrm{SMAI}_{j} & =0.5 * \mathrm{SMAI}_{j-1}+\frac{\mathrm{SA}_{j}}{50}, \\
\mathrm{SMAI}_{1} & =\frac{\mathrm{SA}_{1}}{50} \\
\mathrm{SA}_{j} & =\frac{\left(\mathrm{SW}_{j}-\mathrm{MSW}_{j}\right)}{\left(\mathrm{MSW}_{j}-\mathrm{SW}_{(\min ) j}\right)} * 100, \quad \text { if } \mathrm{SW}_{j} \leq \mathrm{MSW}_{j}, \\
\mathrm{SA}_{j} & =\frac{\left(\mathrm{SW}_{j}-\mathrm{MSW}_{j}\right)}{\left(\mathrm{SW}_{(\max ) j}-\mathrm{MSW}_{j}\right)} * 100, \quad \text { if } \mathrm{SW}_{j}>\mathrm{MSW}_{j},
\end{aligned}
$$

where $\mathrm{SW}_{j}$ is the actual monthly soil moisture at month $j$ and $\mathrm{SW}_{(\max ) j}, \mathrm{SW}_{(\min ) j}$, and $\mathrm{MSW}_{j}$ are the long-term maximum, minimum, and median soil moisture at month $j$, respectively. $\mathrm{SA}_{j}$ is defined as the monthly soil moisture availability with the range of -100 to 100 . SMAI considers both the soil moisture condition at the current month and that of the previous month. The initial value of SMAI was calculated only considering the SA with the range of -2 to 2 . With the iterative computations, the range of SMAI values is -4 to 4 [14].

Considering that the soil moisture observation data are limited and the geographical distribution is uneven [19], while with the advance of remote sensing, soil moisture data can be extracted in a short time for large areas. With the continuous improvement and development of global soil water monitoring, the global land surface data products by the Global Land Data Assimilation System (GLDAS) have been widely used in related research. The applicability of these data in North China has also been documented [20]. Therefore, we used GLDAS data as input data for soil drought index calculations in this study. The monthly soil moisture data (unit: $\mathrm{kg} / \mathrm{m}^{2}$ ) of GLDAS_NOAH025 (http://disc.sci.gsfc.nasa.gov/hydrology/data-holdings) were used in this study, and the data version is 2.1 , which consists of 4 layers of soil water $(0-0.1 \mathrm{~m}, 0.1-0.4 \mathrm{~m}, 0.4-1.0 \mathrm{~m}$, and $1.0-2.0 \mathrm{~m}$ underground, resp.) with $0.25^{\circ} \times 0.25^{\circ}$ spatial resolution, about $25 \mathrm{~km} \times 25 \mathrm{~km}$.

As an indicator of meteorological drought monitoring, SPEI has multiple timescale features while considering the precipitation and potential evapotranspiration simultaneously. Studies have shown that the SPEI is in good agreement with the actual drought condition both in China and in North China $[21,22]$. Therefore, TRMM and MODIS global evapotranspiration product data are used to calculate the SPEI in this study, and the relationship between SPEI and SMAI will be analyzed for the applicability validation of SMAI in our study area.

3.2. Vegetation Monitoring Index. The normalized difference vegetation index (NDVI) is the most widely used vegetation index. It has a strong correlation with vegetation coverage, vegetation growth status, leaf area, biomass, chlorophyll, and other physiological parameters [23]. The vegetation condition index (VCI) obtained by normalizing NDVI for many years can be used as an indicator of the degree of environmental stress. It is widely used in agricultural drought monitoring and other fields. The formula is as follows. 


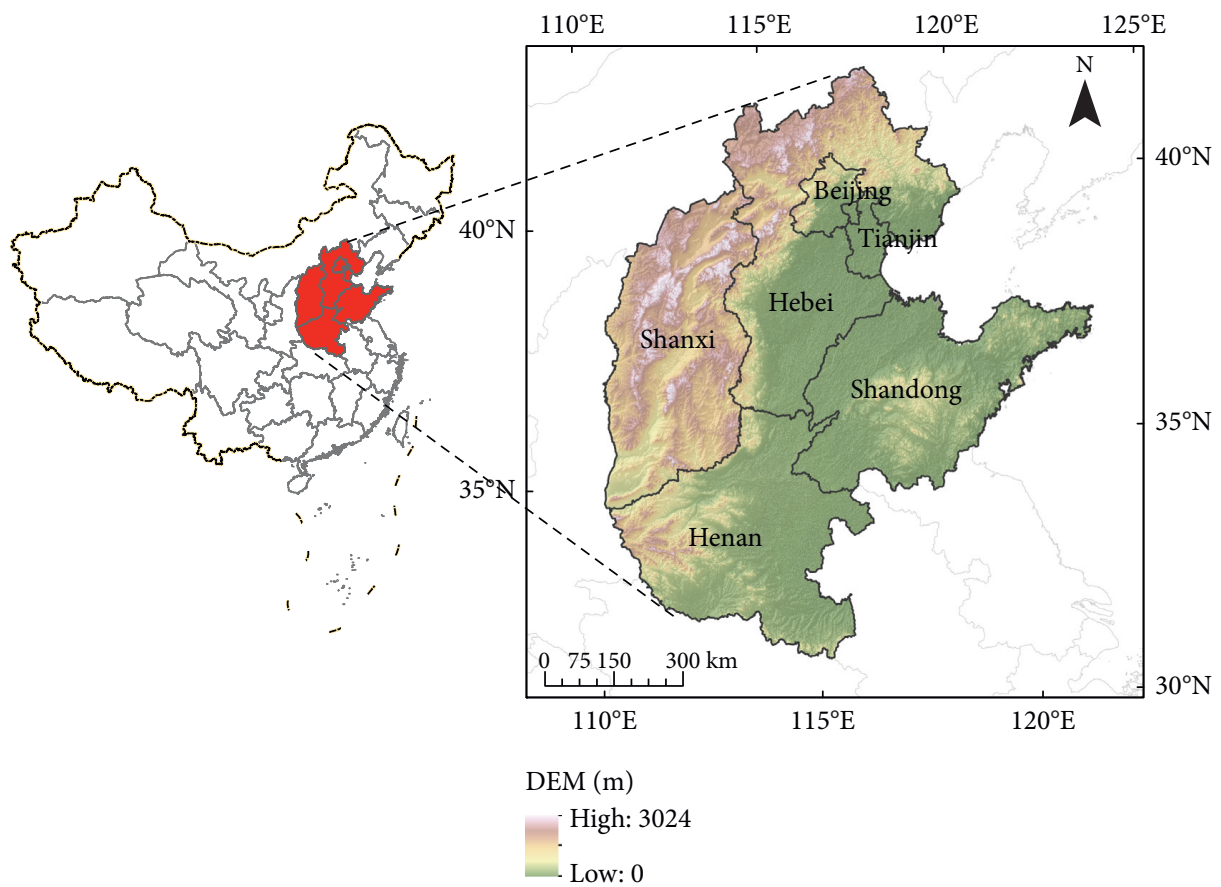

Figure 1: Location of the study area.

$$
\mathrm{VCI}=100 \times \frac{\mathrm{NDVI}_{\mathrm{cur}}-\mathrm{NDVI}_{\text {min }}}{\mathrm{NDVI}_{\text {max }}-\mathrm{NDVI}_{\text {min }}},
$$

where $\mathrm{NDVI}_{\text {cur }}, \mathrm{NDVI}_{\text {max }}$, and $\mathrm{NDVI}_{\text {min }}$ are monthly NDVI, multiyear maximum NDVI, and multiyear minimum NDVI, respectively, for each grid cell. VCI changes from 0 to 100 corresponding to changes in vegetation condition from extremely unfavorable to optimal. Because the effect of drought on vegetation growth was mainly in the growing season and the growing season of vegetation and crops in the North China is usually in April to October, the monthly $1 \mathrm{~km}$ MOD13A3 NDVI product (https://pdaac.usgs.gov/ dataset_discovery/modis/modis_products_table/mod13a3) of growing season was used in this study.

3.3. Trend Analysis. In this paper, the temporal evolutions of drought and vegetation index were estimated using the slope of the time series of data. Taking the monthly variation of SMAI as an example, the formula is as follows:

$$
\theta_{\text {slope }}=\frac{n \times \sum_{i=1}^{n}\left(i \times M_{\mathrm{SMAI}_{i}}\right)-\sum_{i=1}^{n} i \sum_{i=1}^{n} M_{\mathrm{SMAI}_{i}}}{n \times \sum_{i=1}^{n} i^{2}-\left(\sum_{i=1}^{n} i\right)^{2}},
$$

where $n$ is the total number of months and $M_{\mathrm{SMAI}_{i}}$ is the SMAI value in $i$ months.

3.4. Correlation Analysis. In order to analyze the response of vegetation growth to drought, the Pearson correlation analysis was done between SMAI and VCI. Because the variables are normal continuous variables, their correlation degree can be measured by the Pearson correlation coefficient.
TABle 1: The correlation coefficient between SMAI and SPEI in North China.

\begin{tabular}{lccccc}
\hline $\begin{array}{l}\text { Correlation } \\
\text { coefficient }\end{array}$ & SPEI-1 & SPEI-3 & SPEI-6 & SPEI-9 & SPEI-12 \\
\hline SMAI-1 & $\mathbf{0 . 5 1}$ & $\mathbf{0 . 8 5}$ & $\mathbf{0 . 7 4}$ & $\mathbf{0 . 6 3}$ & $\mathbf{0 . 5 9}$ \\
SMAI-2 & $\mathbf{0 . 2 1}$ & $\mathbf{0 . 4 9}$ & $\mathbf{0 . 6 8}$ & $\mathbf{0 . 8 0}$ & $\mathbf{0 . 8 4}$ \\
SMAI-3 & 0.06 & $\mathbf{0 . 2 8}$ & $\mathbf{0 . 5 2}$ & $\mathbf{0 . 7 3}$ & $\mathbf{0 . 8 3}$ \\
SMAI-4 & 0.09 & $\mathbf{0 . 2 2}$ & $\mathbf{0 . 4 4}$ & $\mathbf{0 . 6 3}$ & $\mathbf{0 . 7 6}$ \\
\hline
\end{tabular}

Note: $r$ in bold indicates that it reached a significance level of $\alpha=0.01$.

3.5. Drought Event Identification and Its Relationship with Meteorological Conditions. It is difficult to capture both the duration and the location of the drought simultaneously based on the temporal and spatial characteristics, respectively. Therefore, the combination of the above two characteristics can identify the duration, influence area, and severity of drought. In the past, the drought index in a three-month scale, SPI-3, RDI-3 (reconnaissance drought index), and SPEI-3 were selected for seasonal drought study.

With the SMAI calculated for each $0.25^{\circ} \times 0.25^{\circ}$ grid from 2001 to 2015, drought events are extracted using the proposed space-time continuum identification method. According to the study area and the data spatial resolution, we will identify drought events that are over three months and cover an area of more than $10000 \mathrm{~km}^{2}$. A threshold value of SMAI-1 should be set to identify the drought condition.

For each month during 2001-2015, each successive arid region is marked as a uniquely coded drought patch. When the area of overlapping regions of two consecutive months of dry patches is greater than $10000 \mathrm{~km}^{2}$, it is marked as the same drought event. So, the area where the drought occurs, 


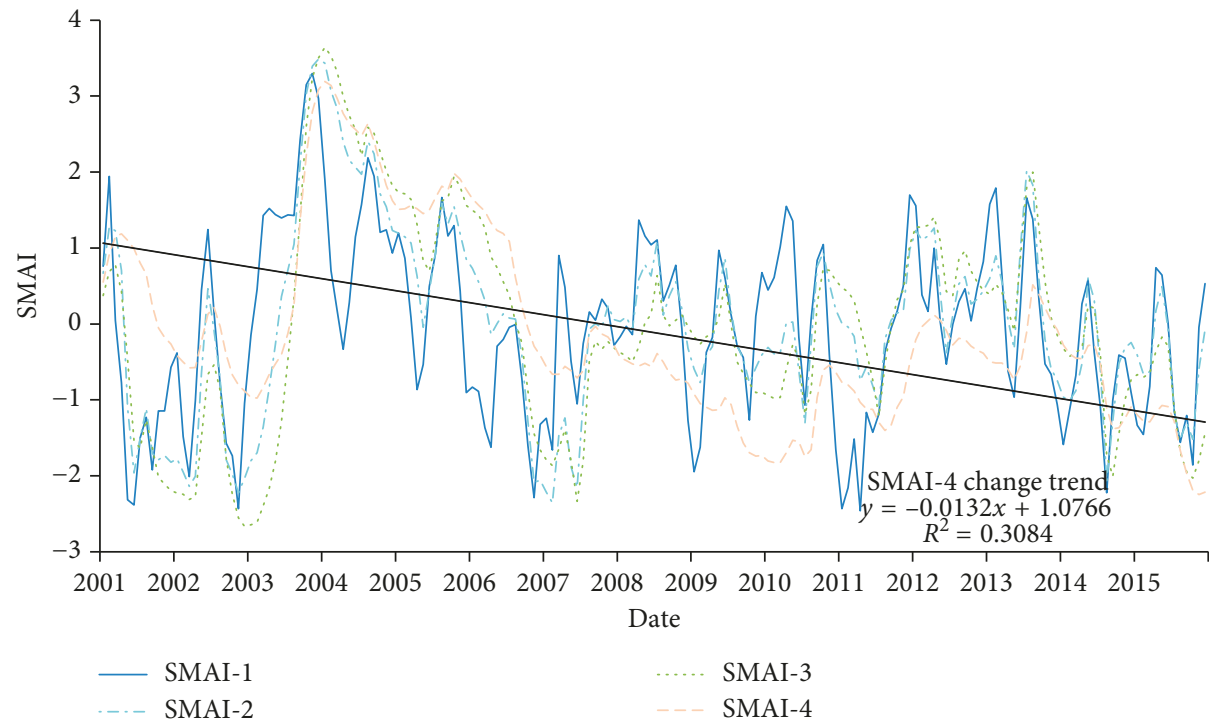

Figure 2: Monthly time series of the average SMAI in North China.
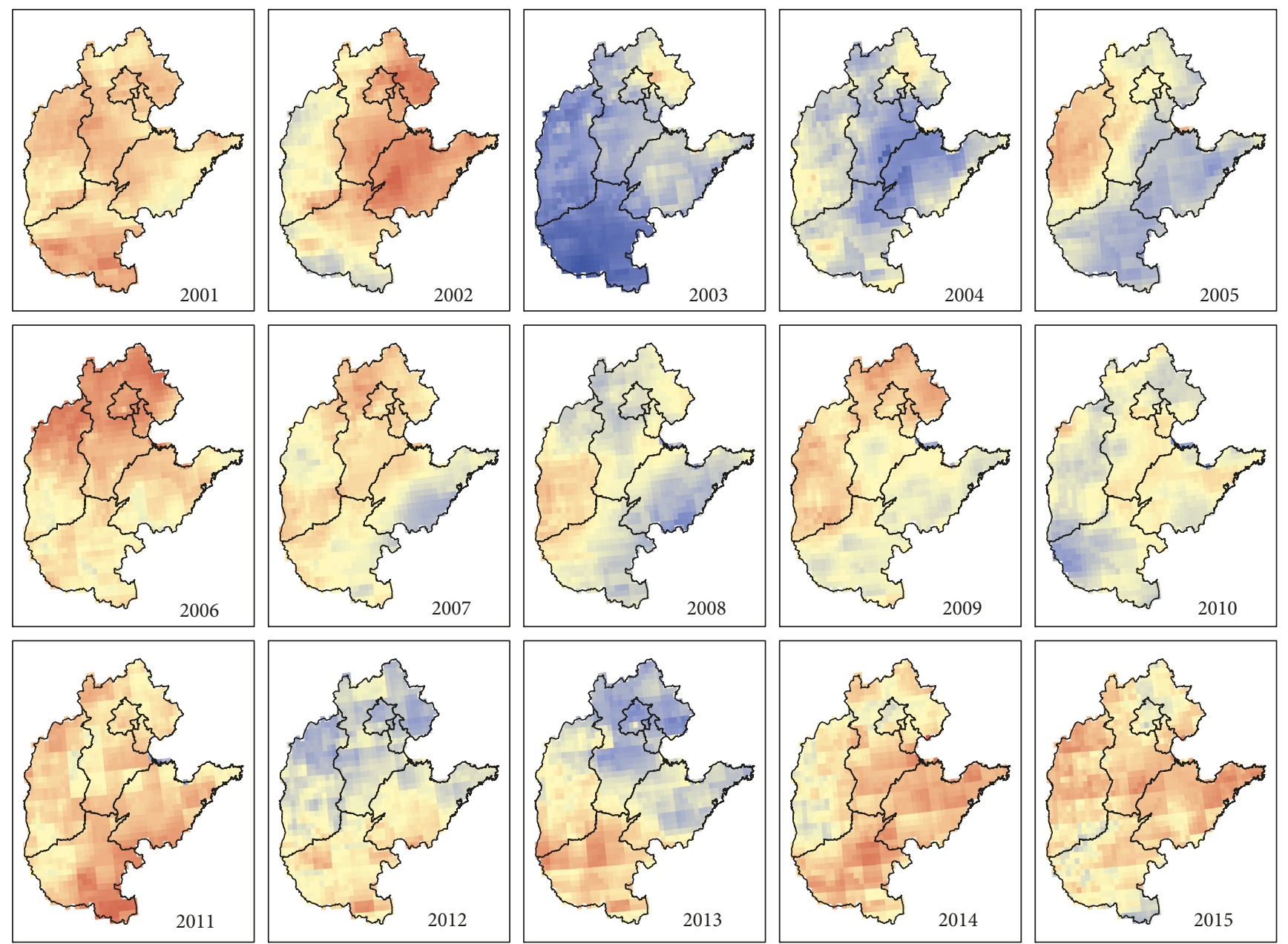

SMAI

- 3.5

$-3.5$

Figure 3: Spatial distribution of annual SMAI-1 in North China during 2001-2015. 


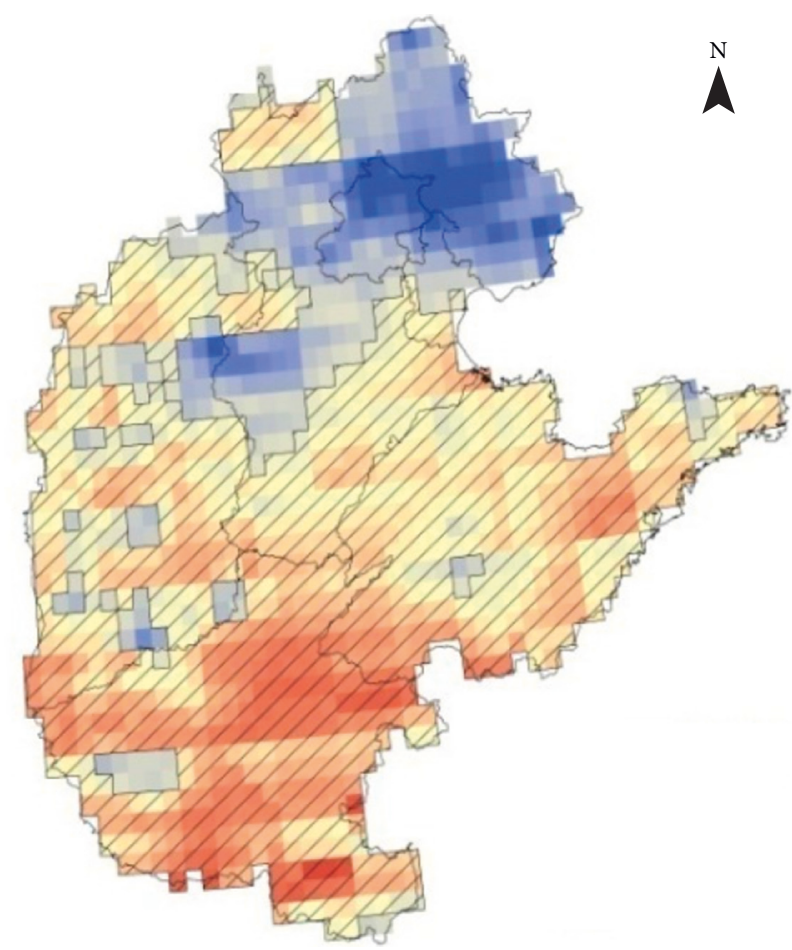

Aridification SMAI trend
High: 0.017
Low: -0.017

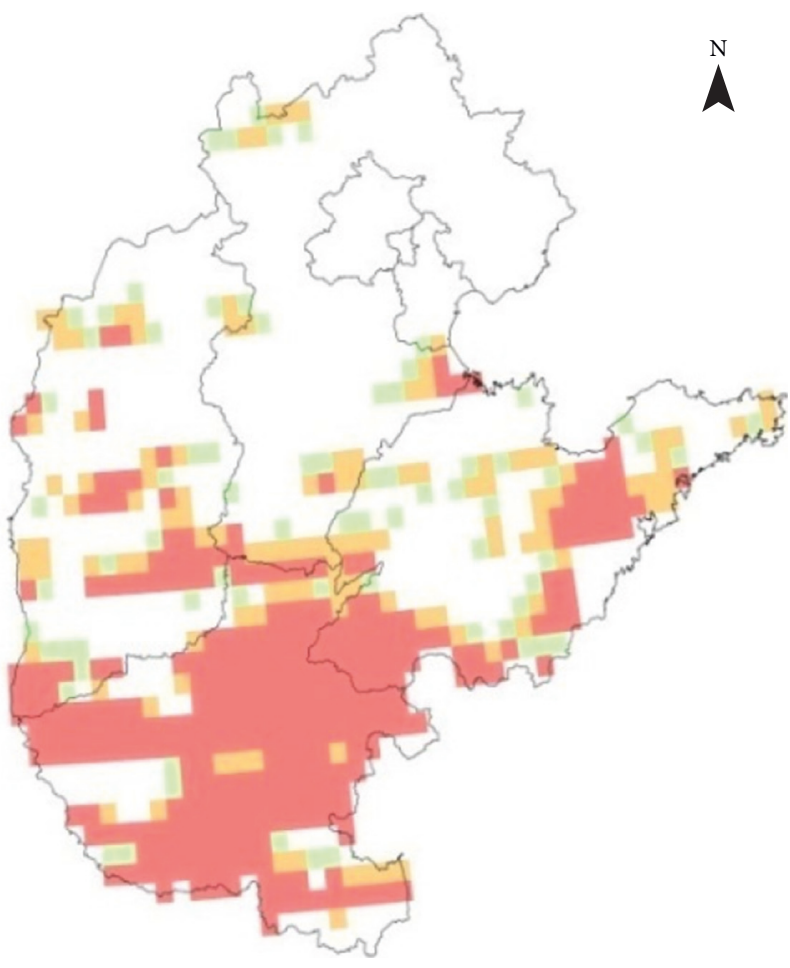

Aridification significance level
$\begin{aligned} \alpha & =0.01 \\ \alpha & =0.05 \\ \alpha & =0.1\end{aligned}$

(b)

FIgURE 4: Spatial distribution of monthly SMAI-1 change slope (a) and significance level (b).

its duration, and the severity of the drought can be tracked [24].

Drought are closely related with precipitation and temperature, so we also collected the average precipitation and temperature in each month from 2001 to 2015 (data from China Meteorological Data Network: www.data.cma.cn) and calculated the precipitation and temperature anomalies during the drought period.

\section{Results and Discussion}

4.1. Relationship between SPEI and SMAI. Different drought indices are concerned with different perspectives of drought. The SPEI focuses on the meteorological drought, and the SMAI focuses on the soil drought. The various links of the drought are interrelated. In order to verify the consistency and accuracy of the drought index selected for this study, the correlation coefficient is calculated, including four-layer soil drought conditions reflected by SMAI and five timescale meteorological drought characteristics reflected by SPEI. The monthly SMAI was calculated by the soil moisture data of the GLDAS in the four soil layers (SMAI-1: $0.0 \mathrm{~m}-0.1 \mathrm{~m}$, SMAI-2: $0.1 \mathrm{~m}-0.4 \mathrm{~m}$, SMAI-3: $0.4 \mathrm{~m}-1.0 \mathrm{~m}$, and SMAI-4: $1.0 \mathrm{~m}-2.0 \mathrm{~m}$ ) in 2001-2015. The SPEI has an advantage of the multiple timescales. SPEI-1, SPEI-3, SPEI-6, SPEI-9, and
SPEI-12 are calculated, respectively, on 1-, 3-, 6-, 9-, and 12 -month scales. For example, SPEI-1 indicates the degree of meteorological drought in the current month, and SPEI-3 indicates the comprehensive meteorological drought situation including the current month and the previous two months.

The results (in Table 1) showed that the correlation coefficient of SMAI-1 and SPEI-3 was the highest and reached a significance level of $\alpha=0.01$. Overall, SMAI responded with SPEI, with the increase in timescale and the decrease in soil depth, and the correlation coefficient between SMAI and SPEI increased.

4.2. Temporal and Spatial Variations of Drought in North China. Time series of the monthly mean SMAI of the four soil layers in the 180 months are shown in Figure 2 so as to reflect the change trend of soil drought in North China.

The results showed that the variation trends of SMAI in the four layers were almost the same in the past 15 years in the North China region. However, SMAI-2, SMAI-3, and SMAI-4 have a time lag of 1 to 7 months compared with SMAI-1. The overall change trends of SMAI decreased; however, the change trends of SMAI in the top three soil layers were not significant, and only the trend of SMAI-4 was 
TABLE 2: Drought events in North China during 2001-2015.

\begin{tabular}{|c|c|c|c|c|c|c|}
\hline ID & Period & $\begin{array}{l}\text { Duration } \\
\text { (months) }\end{array}$ & $\begin{array}{c}\text { Area } \\
\left(\mathrm{km}^{2}\right)\end{array}$ & Location & $\begin{array}{c}\text { Integrated drought } \\
\text { severity index }\end{array}$ & $\begin{array}{c}\text { China flood and drought disaster } \\
\text { bulletin }(2006-2015)\end{array}$ \\
\hline 1 & 200104-200201 & 10 & 685707 & $\begin{array}{l}\text { Whole area to the southern part of } \\
\text { the study area }\end{array}$ & -12366 & \\
\hline 2 & 200112-200204 & 5 & 439073 & $\begin{array}{c}\text { Eastern part of Hebei to Hebei and } \\
\text { Shandong }\end{array}$ & -4399 & \\
\hline 3 & $200207-200301$ & 7 & 570604 & Shandong & -8519 & \\
\hline 4 & 200402-200405 & 4 & 90595 & Southern part of Shanxi & -489 & \\
\hline 5 & $200503-200505$ & 3 & 228620 & $\begin{array}{c}\text { Central and southern parts of } \\
\text { Shanxi }\end{array}$ & -1421 & \\
\hline 6 & 200509-200605 & 9 & 381425 & $\begin{array}{l}\text { Central and northern parts of } \\
\text { Shanxi to Hebei }\end{array}$ & -7770 & $\begin{array}{c}\text { Rainfall continued to be low and } \\
\text { the temperature picked up } \\
\text { around March } 2006 \text { in most of } \\
\text { the areas in the north of Yellow } \\
\text { River }\end{array}$ \\
\hline 7 & 200609-200702 & 6 & 560884 & $\begin{array}{l}\text { Whole area to northern and } \\
\text { eastern parts of the study area }\end{array}$ & -7516 & $\begin{array}{l}\text { During autumn and winter in } \\
\text { 2006, drought occurred in the } \\
\text { eastern part of North China }\end{array}$ \\
\hline 8 & 200706-200709 & 4 & 159561 & $\begin{array}{c}\text { Northern part of Beijing-Tianjin- } \\
\text { Hebei }\end{array}$ & -1153 & $\begin{array}{l}\text { In early June } 2007 \text {, drought } \\
\text { continued to develop in most of } \\
\text { North China }\end{array}$ \\
\hline 9 & 200811-200904 & 6 & 520993 & Most part of the study area & -5391 & $\begin{array}{l}\text { After mid-November } 2008, \\
\text { precipitation was less than } \\
\text { normal in most parts of the } \\
\text { country, which threatened the } \\
\text { growth of winter wheat in North } \\
\text { China }\end{array}$ \\
\hline 10 & $200908-201001$ & 6 & 140548 & $\begin{array}{c}\text { Northern part of Beijing-Tianjin- } \\
\text { Heijing to the northern part of } \\
\text { Hebei }\end{array}$ & -1728 & $\begin{array}{l}\text { From late July to late August } \\
\text { 2009, due to less rainfall and high } \\
\text { temperature, the drought in } \\
\text { some parts of North China } \\
\text { progressed, and severe drought } \\
\text { appeared in the northern part of } \\
\text { Hebei and northern and } \\
\text { southern parts of Shanxi }\end{array}$ \\
\hline 11 & 201006-201009 & 4 & 352889 & $\begin{array}{c}\text { Eastern part of Hebei to whole } \\
\text { Hebei to the northern part of } \\
\text { Shanxi }\end{array}$ & -1488 & $\begin{array}{l}\text { From June to July 2010, most } \\
\text { areas in North China } \\
\text { experienced continuous high } \\
\text { temperature and light rainy } \\
\text { weather. In June 2010, } \\
\text { precipitation in Shanxi } \\
\text { continued to be low, with the } \\
\text { highest temperature in the same } \\
\text { period since } 1961\end{array}$ \\
\hline 12 & 201011-201109 & 11 & 673135 & $\begin{array}{c}\text { Whole study area to the southern } \\
\text { part of the study area }\end{array}$ & -14835 & $\begin{array}{c}\text { From October } 2010 \text { to February } \\
\text { 2011, precipitation in Henan and } \\
\text { Shandong dropped by more than } \\
80 \% \text { over the same period of } \\
\text { previous years }\end{array}$ \\
\hline 13 & 201109-201111 & 3 & 86590 & Northern part of Hebei & -577 & \\
\hline 14 & 201206-201209 & 4 & 185811 & $\begin{array}{l}\text { Southern part of Shandong and } \\
\text { southern part of Henan }\end{array}$ & -1073 & $\begin{array}{l}\text { In June 2012, the precipitation } \\
\text { continued to be less than normal } \\
\text { in most of Yellow River and } \\
\text { Huaihe area (Huanghuai) }\end{array}$ \\
\hline 15 & 201210-201305 & 8 & 349892 & $\begin{array}{c}\text { Junction of Shanxi and Henan to } \\
\text { the southwestern part of the study } \\
\text { area }\end{array}$ & -2851 & \\
\hline 16 & 201309-201404 & 8 & 392483 & Henan to Shandong & -4783 & $\begin{array}{l}\text { After the autumn of } 2013 \text {, } \\
\text { precipitation continued to be } \\
\text { relatively low in the southwestern } \\
\text { part of North China and the } \\
\text { northwestern part of Huanghuai, } \\
\text { threatening the sowing and } \\
\text { growth of winter wheat }\end{array}$ \\
\hline
\end{tabular}


TABle 2: Continued.

\begin{tabular}{ccccccc}
\hline ID & Period & $\begin{array}{c}\text { Duration } \\
\text { (months })\end{array}$ & $\begin{array}{c}\text { Area } \\
\left(\mathrm{km}^{2}\right)\end{array}$ & Location & $\begin{array}{c}\text { Integrated drought } \\
\text { severity index }\end{array}$ & $\begin{array}{c}\text { China flood and drought disaster } \\
\text { bulletin }(2006-2015)\end{array}$ \\
\hline $17 \quad 201406-201412$ & 7 & 575860 & $\begin{array}{c}\text { Henan and Shandong to the } \\
\text { northern part of the study area }\end{array}$ & -5560 & $\begin{array}{c}\text { During June to late August 2014, } \\
\text { the temperature was high and the } \\
\text { rainfall was low in North China } \\
\text { From December 2014 to April }\end{array}$ \\
$18 \quad 201501-201503$ & 3 & 58077 & Central part of Henan & -303 & $\begin{array}{c}\text { 2015, the precipitation in Henan } \\
\text { was the fourth lowest since 1961 } \\
\text { From June to July in 2015, the } \\
\text { rainfall was less than normal and } \\
\text { the temperature was high in most } \\
\text { parts of North China. }\end{array}$ \\
\hline
\end{tabular}

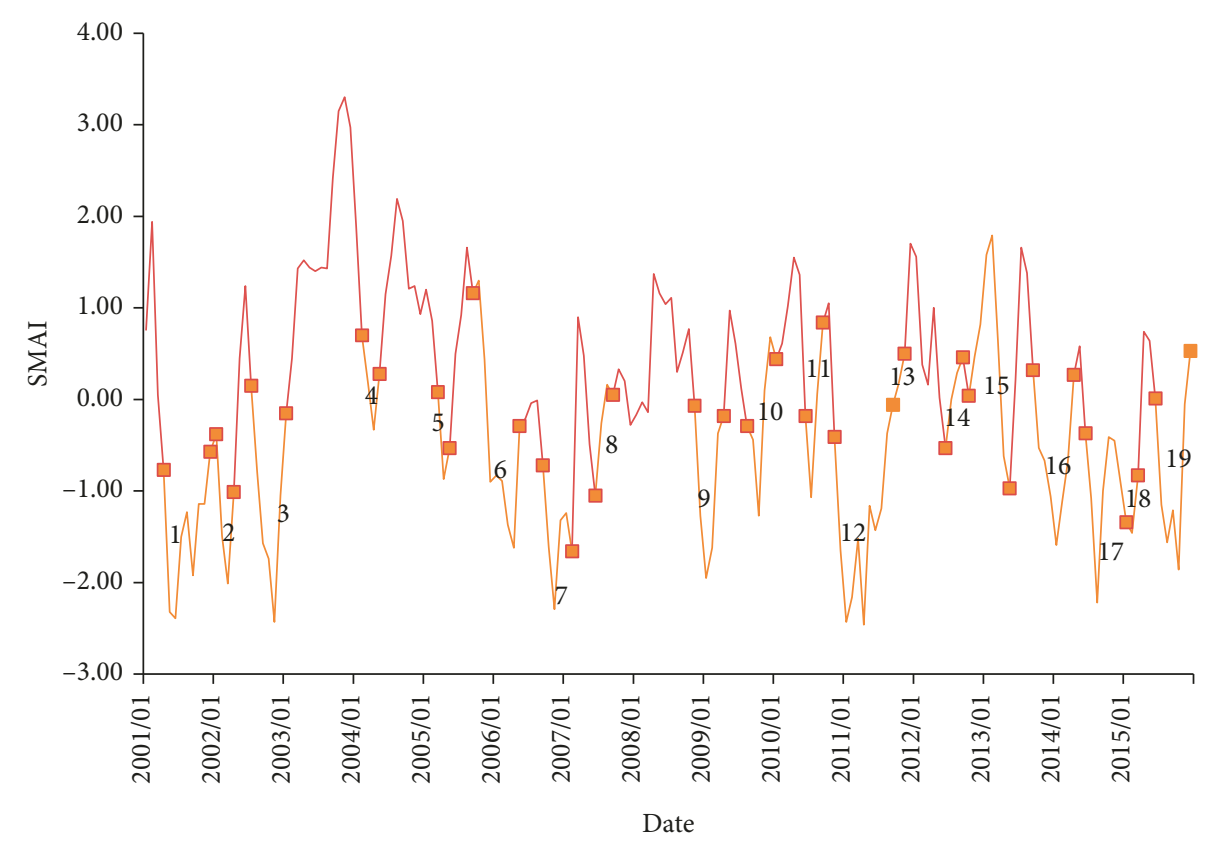

FIgURE 5: The time period of 19 persistent drought events (orange) in North China during 2001-2015 marked on monthly time series of the average SMAI (red).

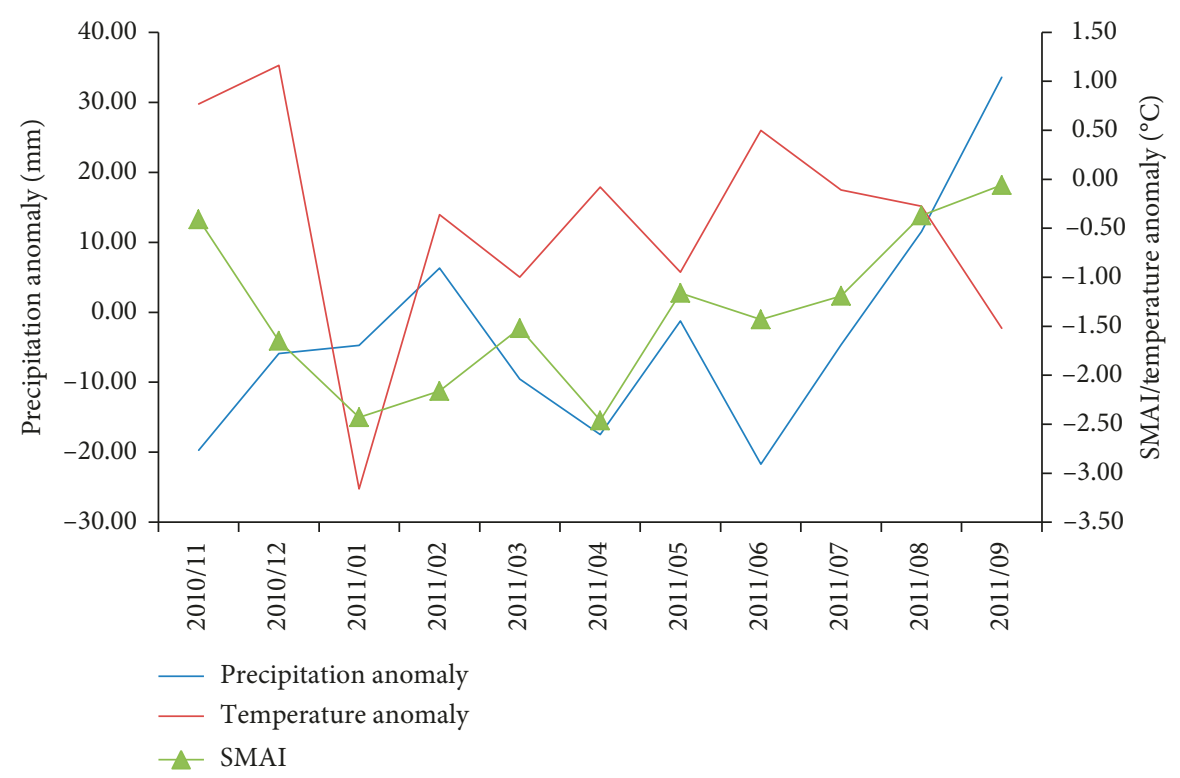

FIgure 6: Monthly SMAI and precipitation and temperature anomalies during November 2010 to September 2011. 

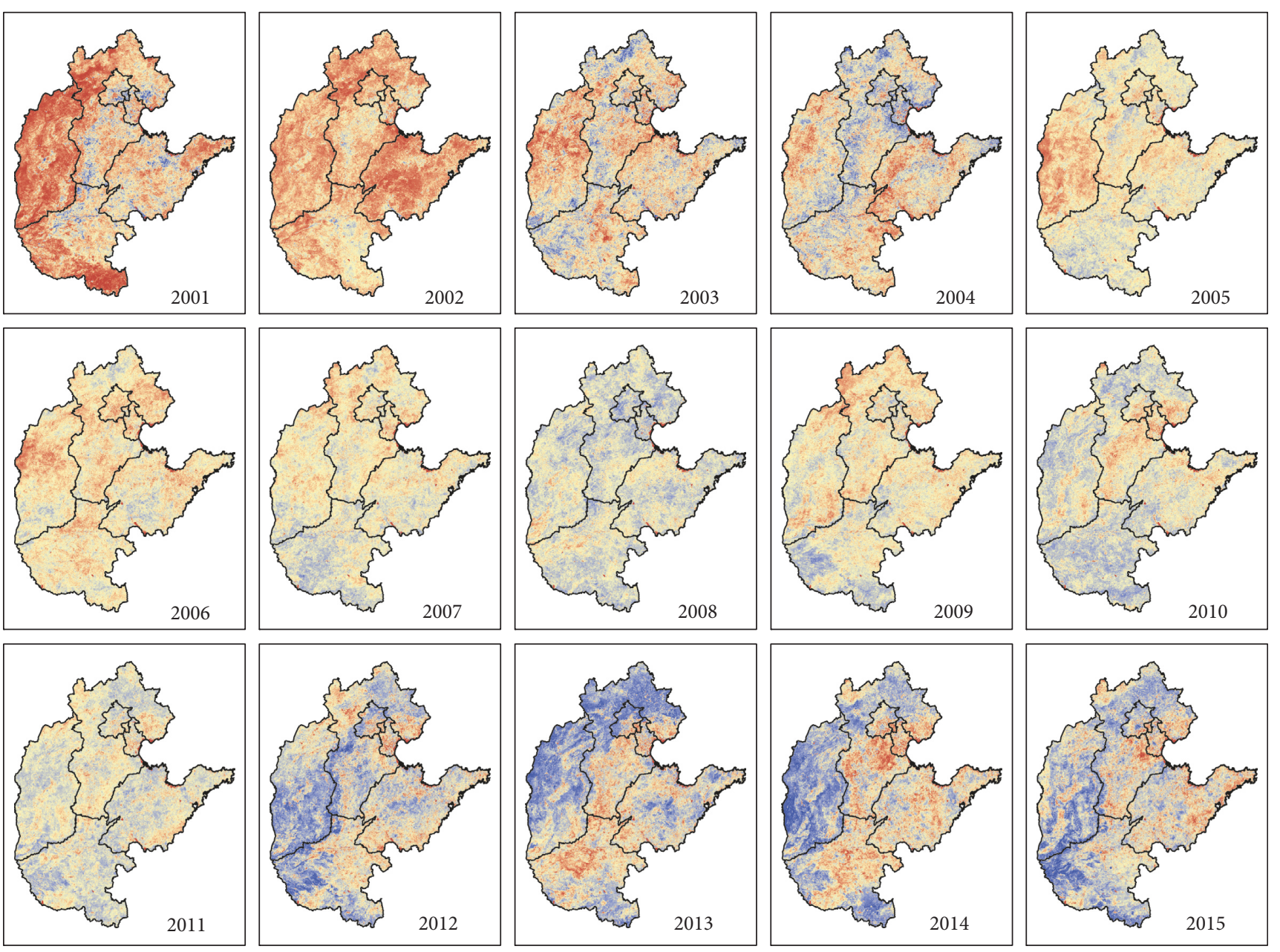

$\stackrel{\text { VCI }}{-100}$

FIgURE 7: Spatial distribution of annual growing season VCI in North China during 2001-2015.

significant and it reached a significance level of $\alpha=0.01$. The results indicated that the degree of soil drought increased.

The values and variation among SMAI in the first three layers are similar, while SMAI-4 has the smallest fluctuation. Taking SMAI-1 as an example, the soil moisture condition was the best during 2003 to 2005, and there was a significant long-term drought period before and after this time. From the end of 2003 to the end of 2006, the average SMAI value dropped most significantly from 3.30 to -2.29 . After that, SMAI fluctuated up and down around 0 , declining sharply in 2007, 2009, and 2011, and soil drought indices reached low values. The drought in 2014 was also severe; on average, SMAI was negative for ten months in 2014.

Considering that the values of SMAI in the top three layers are similar, the property of surface soil is closely related to vegetation growth. The annual SMAI-1 was calculated by the mean of monthly SMAI-1. The spatial distributions of annual SMAI-1 during 2001-2015 are shown in Figure 3. The results indicated that the annual SMAI-1 was relatively high in 2003, 2004, and 2005 in the whole study area, and there is no obvious drought area. On the contrary, the annual SMAI-1 was relatively low in 2001, 2002, 2006, $2007,2011,2014$, and 2015. In order to facilitate the comparison of similar studies, the zero baseline for SMAI was adopted to analyze soil drought/moistness. The area where the SMAI is less than 0 is considered to be drought, and the drought area accounted for 97\%, 79\%, 90\%, 68\%, 94\%, 83\%, and $81 \%$, respectively, in the above year.

The monthly slope of SMAI-1 was calculated by formula (3) for each pixel, and the result is shown in Figure 4 . The negative value indicates that the area tends to be drought, and with the decrease of the slope value, the degree of drought increases. The results in Figure 4 showed that the trend of drying was the most obvious in the southern part of the study area, and the trend of wetting was obvious in the north. The area where the slope of SMAI is less than 0 is considered to be drying areas, which account for $72 \%$ of the study area, and $50 \%$ of the drying areas reached statistical significance. The degree of drying is more serious in the southern part of the study area, including Henan Province, 


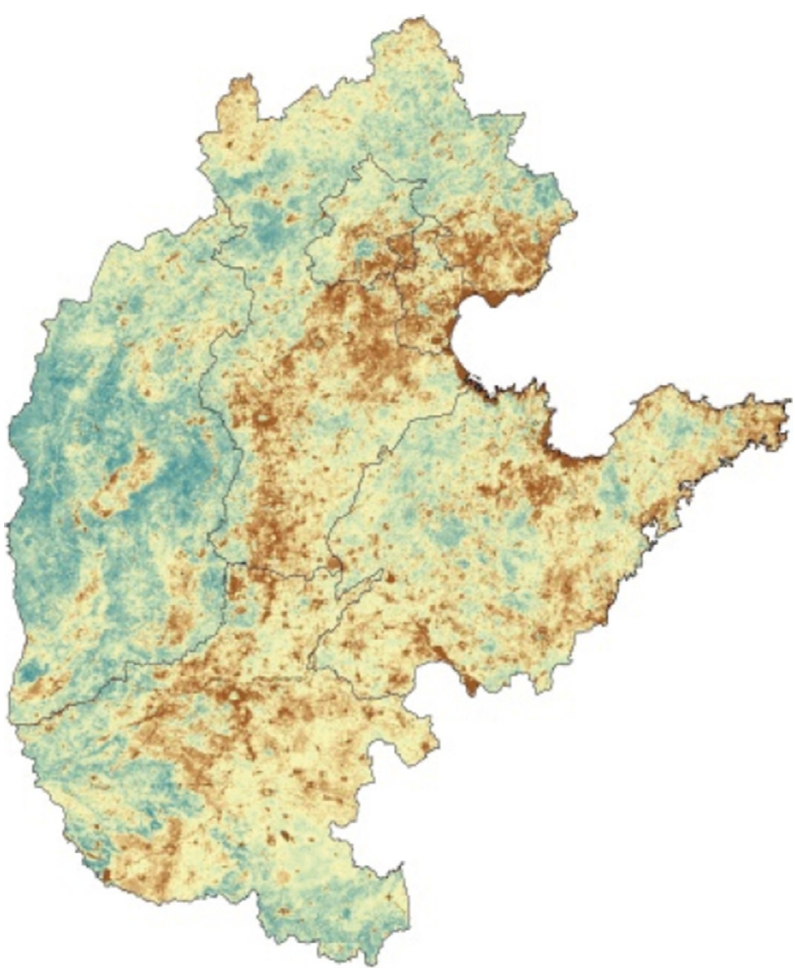

Trend of VCI

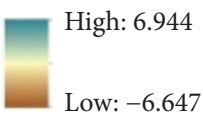

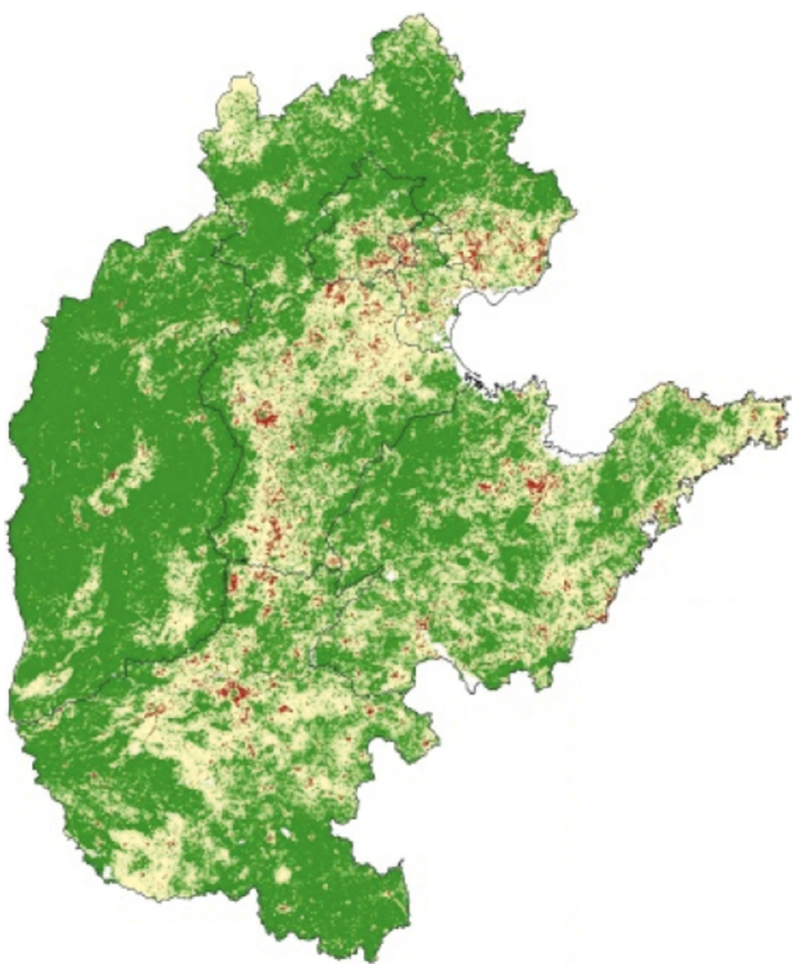

Significance level
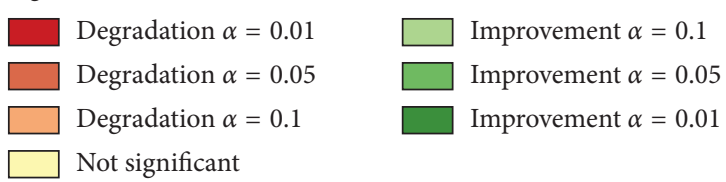

(b)

FIgUre 8: Annual trend and significance level of VCI in North China during 2001-2015.

Shandong Province, and part of the mountainous area in Shanxi Province. The overall situation of soil wetness in the Beijing-Tianjin-Hebei region has improved, especially in the northeastern part of Hebei Province. Overall, SMAI trend analysis reflected that Henan Province tended to be drying significantly during 2001-2015.

4.3. Persistent Drought Events in North China. We tested the threshold of SMAI-1 values with $-1,-1.5$, and -2.0 to detect drought events, and the drought events detected by a value of -1.5 matched well with the records from China flood and drought disaster bulletin (2006-2015). Therefore, the SMAI threshold was set as -1.5 in this study. A total of 19 persistent drought events were detected during 2001-2015 in North China (Table 2), of which the duration is the number of months that the drought event lasts, the area is the maximum area affected by drought during the drought period, and the integrated drought severity index (IDSI) is the sum of the monthly SMAI values in the drought area during the drought period.

The time period of 19 persistent drought events in North China during 2001-2015 was drawn on the monthly time series of average SMAI in Figure 5. The persistent drought events also occurred when the whole average area was in drought conditions in North China. Because the IDSI can reflect the duration, area, and soil moisture of drought events, we sort the intensity of the 19 drought events by IDSI. The most comprehensive drought event from November 2010 to September 2011 was as long as 11 months, with an IDSI of -14835 , extending $97 \%$ of the study area, followed by the drought from April 2001 to January 2002, which lasted up to 10 months, and almost the entire study area was affected by the above drought events. However, in other time periods, although the overall drought situation in North China was not obvious, drought also occurred in some areas. For example, in Figure 5, the overall drought index in North China in 2004 was above the average, but there were still persistent droughts in southern Shanxi.

In order to verify the accuracy of the drought event identified in the study, the drought duration and distribution reflected by the SMAI were compared with the China flood and drought disaster bulletin records (2006-2015). The results showed in Table 2 that the drought conditions reflected by SMAI are basically consistent with the data records.

Taking one of the most serious drought events as an example, the status of precipitation and temperature during the drought period is analyzed. The drought event began in November 2010 and ended in September 2011, affecting 


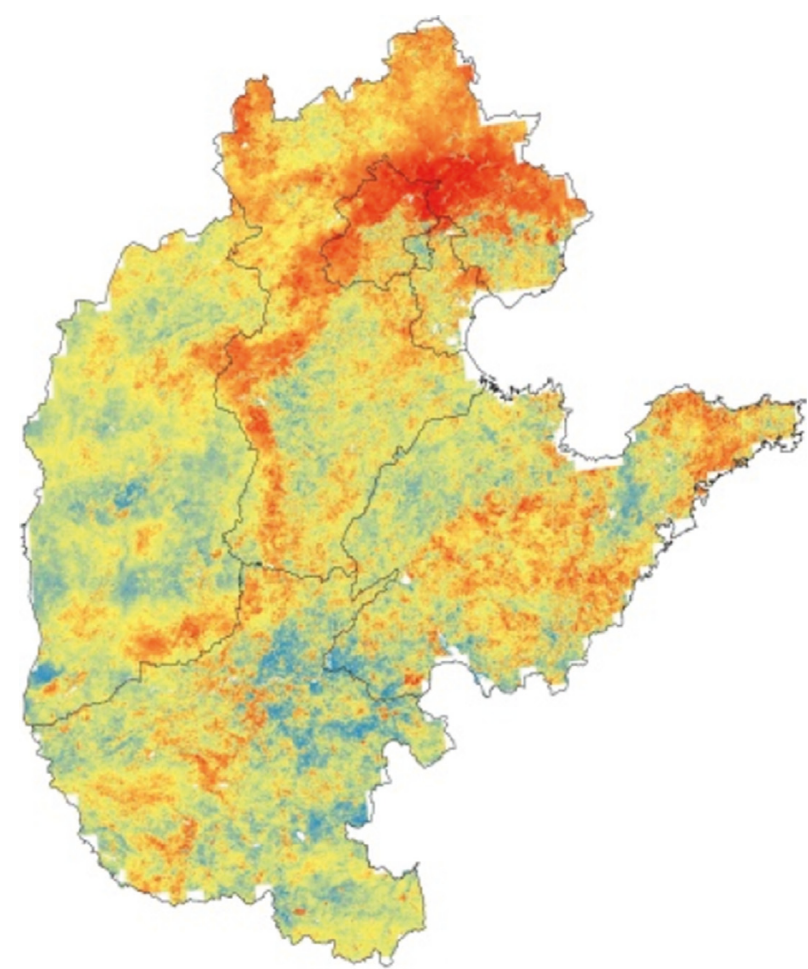

Correlation coefficient $r$

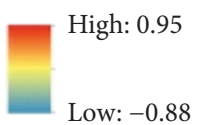

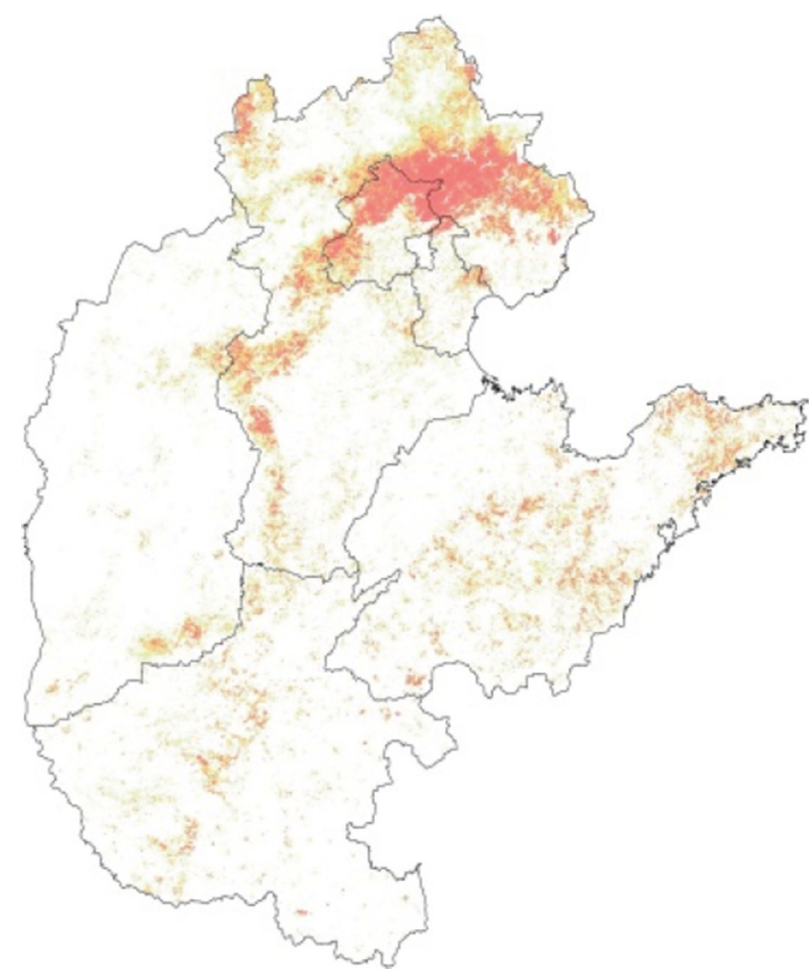

Significance level for positive correlation

$\square \alpha=0.1$

$\alpha=0.05$

$\alpha=0.01$

(a)

(b)

FIGURE 9: Spatial distribution of correlation analysis between SMAI and VCI in North China.

most of the study area. The monthly precipitation anomaly, the temperature anomaly, and the SMAI during the drought event are shown in Figure 6. It can be seen from November 2010 to June 2011 that the precipitation in the study area has been at a low level. However, no obvious high temperature appeared during this period, and the drought was mainly caused by the less rainfall. The calculated SMAI of the same period also shows a similar rule to the change in precipitation.

4.4. Temporal and Spatial Variations of Vegetation in North China. Due to the phenology of vegetation, the vegetation condition varied over time. VCI normalizes NDVI and allows for a comparison of different ecosystems. The results showed that the VCI value was the lowest in April, followed by October, May, and June in North China. The monthly mean values of VCI in these above months are below 50, indicating that the vegetation status in these months was poor. In order to explore the spatial distribution of the vegetation index in North China, we calculated the mean value of growing season VCI in North China (in Figure 7). In 2001 and 2002, the VCI value was much lower than that in other years. Then, the vegetation status has a stable improvement in whole regions until 2011. Since 2012, the vegetation condition had improved more significantly, especially in the northern and western regions of the study area.

The trend analysis method was also used to study the spatial-temporal variation characteristics of vegetation. The spatial distribution of the annual VCI linear trend is shown in Figure 8. The slope value above or below 0 indicates that the vegetation condition is improved or degenerated.

The trend of VCI data indicated that $88 \%$ of the areas were improved in the study area, mainly distributed in the high-altitude area. In contrast, the area of vegetation degradation was distributed in the southeast part with low altitude. It is concentrated in the southern part of Henan Province, the central and eastern coastal areas of Hebei Province, and the small part of coastal areas in Shandong. For the temporal change of VCI, $70.41 \%, 65.00 \%$, and $52.28 \%$ areas reached the positive significance level of $\alpha=0.1, \alpha=0.05$, and $\alpha=0.01$, respectively, while $3.78 \%$, $2.90 \%$, and $1.57 \%$ areas reached the negative significance level of $\alpha=0.1, \alpha=0.05$, and $\alpha=0.01$, respectively.

\subsection{Vegetation Response to Drought in North China}

4.5.1. Response of Annual Vegetation Condition to Drought. To analyze the vegetation response to the drought, we calculated the correlation coefficient between SMAI and 

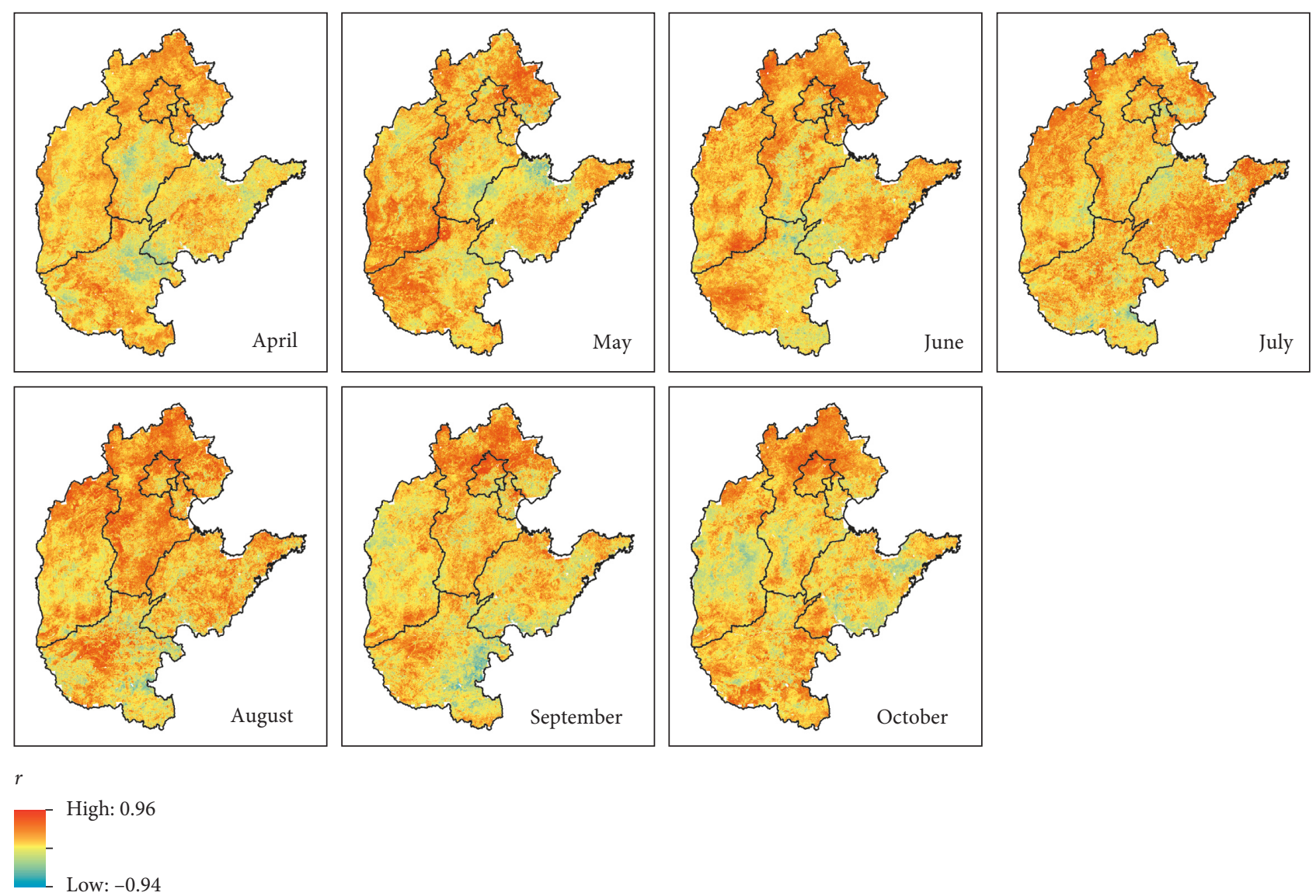

FIgURE 10: Spatial distribution of monthly correlation coefficients between SMAI-1 and VCI in North China.

the corresponding vegetation index at the pixel scale during 2001-2015. The annual values of SMAI-1 were calculated from the average of monthly data of SMAI-1. The SMAI data were resampled to $1 \mathrm{~km}$ by $1 \mathrm{~km}$ spatial resolution. MODIS Land Cover data in MCD12Q1 in 2013 were used to analyze whether the differences of the drought effects were related to vegetation types. According to the MCD12Q1's IGBP global land cover classification scheme and primary vegetation types in the study area, the land cover data were reclassified into eight categories, including woodland, grassland, shrub, farmland, city, bareland, waterbody, and wetland, and the first four were related with vegetation.

The correlation coefficient between SMAI and VCI is shown in Figure 9(a). There was $76 \%$ of the total area with positive value, with a mean value of 0.30 , and $19 \%, 13 \%$, and $5 \%$ areas reached the positive significance level of $\alpha=0.1, \alpha=0.05$, and $\alpha=0.01$, respectively. The high positive correlation between SMAI and VCI was mainly distributed in the northeast of Hebei Province, the junction of Hebei Province and Shanxi Province, and the central and eastern parts of Shandong Province. The mean values of the positive correlation coefficient for shrub, woodland, grassland, and farmland were $0.42,0.39,0.32$, and 0.28 , respectively, and none reached the significance level of $\alpha=0.1$.
4.5.2. Response of Monthly Vegetation Condition to Drought. To explore the response of vegetation to soil drought at different phenological periods, we analyzed the relationship between vegetation condition and drought at the monthly scale in the vegetation growing season (from April to October). Through normalization, the VCI eliminates the difference to make vegetation changes comparable on the monthly scale. The response of monthly vegetation condition to drought was analyzed between SMAI and VCI. The results are shown in Figures 10 and 11.

Generally, the results showed that the positive coefficient between SMAI-1 and VCI accounted for almost $91 \%$ of the total area, and about $37 \%$ of them reached the significance level of $\alpha=0.01$, which indicated that surface soil drought affected vegetation significantly in the growing season. Vegetation water demand varies with the vegetation type and seasonal variation. From April to October, the mean values of SMAI-VCI correlation coefficients in the whole study area were $0.161,0.218,0.222,0.223,0.259,0.158$, and 0.171 , respectively, and the positive correlation proportions were $76.9 \%, 78.5 \%, 80.8 \%, 80.2 \%, 81.9 \%, 71.4 \%$, and $73.4 \%$, respectively, with mean values of $0.259,0.322,0.310,0.317$, $0.354,0.293$, and 0.293 .

From the temporal evolution analysis, the correlation coefficient between SMAI and VCI increased from April to August gradually and then decreased significantly from 

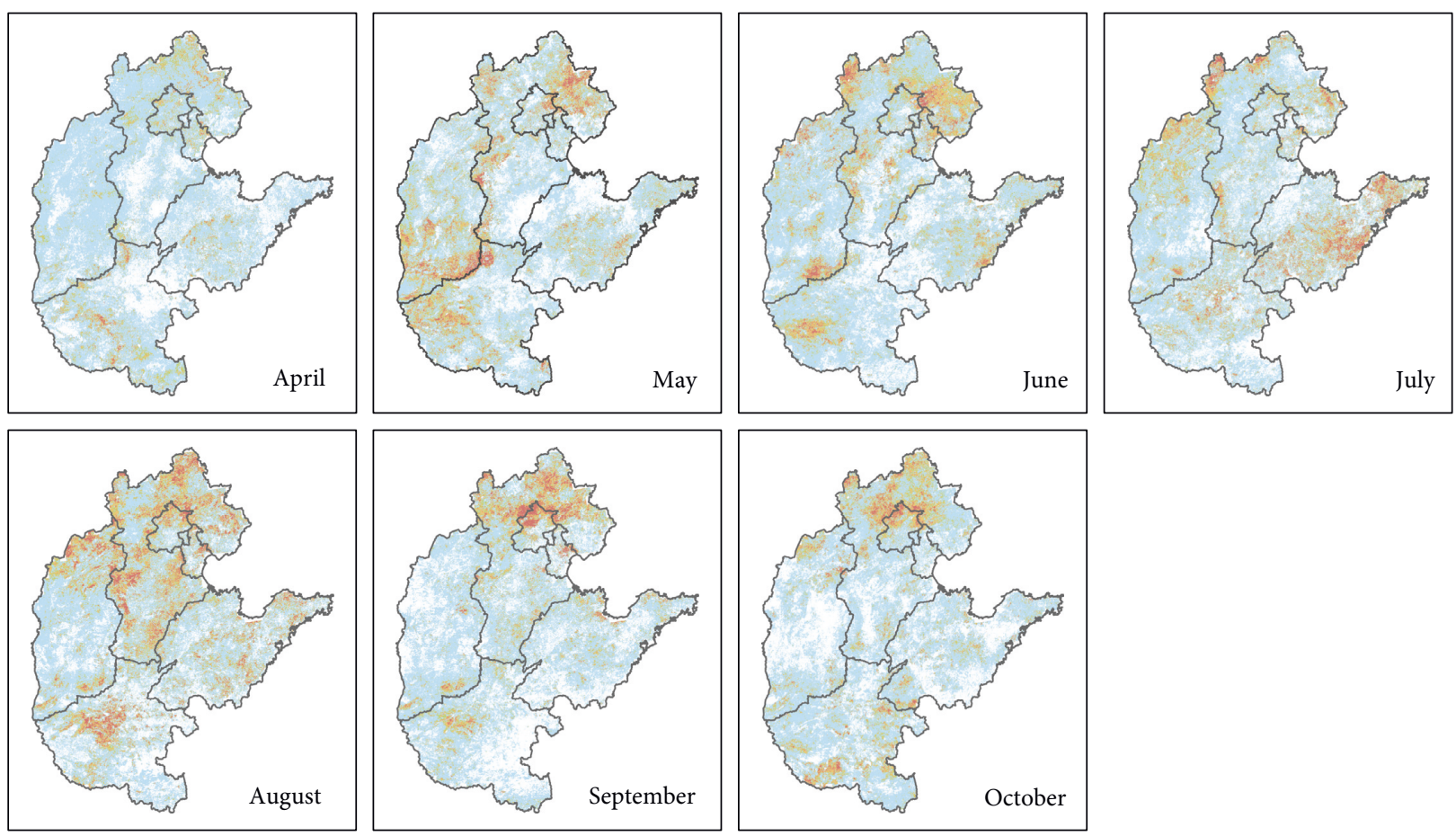

uly

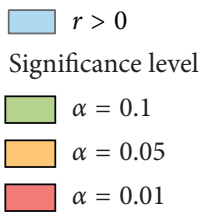

Figure 11: Spatial distribution of the significance level between SMAI-1 and VCI in North China.

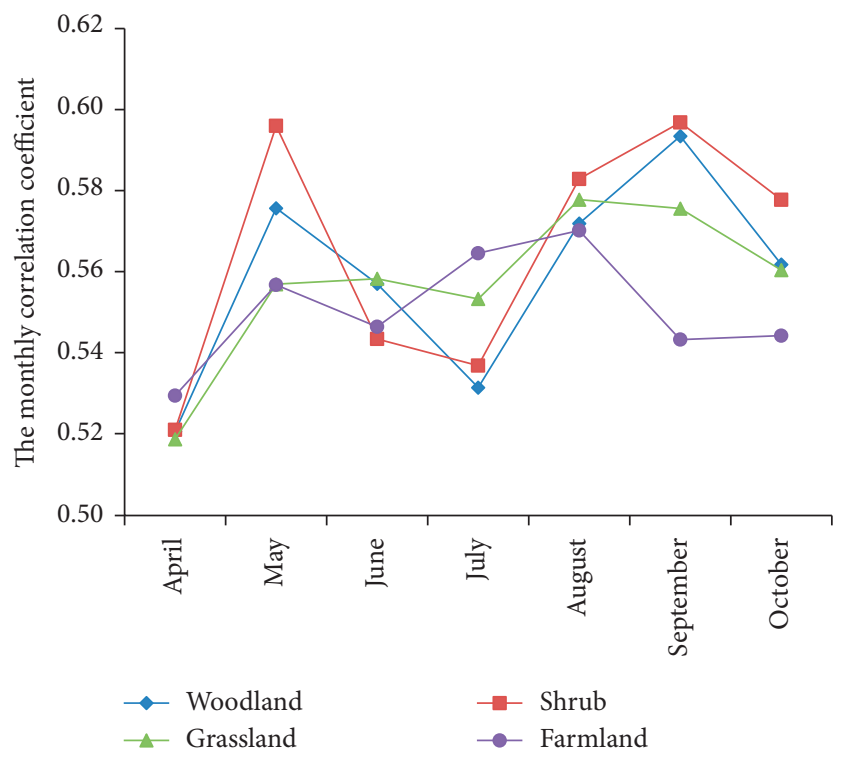

FIGURE 12: The monthly correlation coefficient between SMAI and VCI in different vegetation types.

August to September overall, which indicates the vegetation response to soil drought most significantly in August. In terms of spatial distribution, the correlation coefficient was high in the north part of the study area in the whole growing season, while as for the middle part of the study area, the correlation coefficient was high during May to August.

The monthly mean values of SMAI-VCI correlation coefficients of the four vegetation types in which the significance level reached $\alpha=0.1$ are shown in Figure 12. There are two peaks of the correlation coefficient between SMAI and VCI in the growing season for the four types of vegetations, one occurred in May and the other in August or September. The maximum correlation coefficient of woodland and shrub occurred in September, while for grassland and farmland, it occurred in August. The maximum correlation coefficient between SMAI and VCI for the four types of vegetation decreased by shrub, woodland, grassland, and farmland, which is reasonable, besides that the soil drought, soil fertility, irrigation, and other human interventions have a great influence on crop growth.

\section{Conclusions}

This paper investigated the variation of soil drought and vegetation indices and their correlations during 2001-2015 in North China. The following important conclusions can be drawn from this study:

(1) The SMAI related well with SPEI which is widely used in meteorological drought assessment, and drought events detected by SMAI matched well with the "China flood and drought disaster bulletin (2006-2015)”. 
(2) The monthly average drought degree by the timeseries SMAI has an increasing tendency generally in the study area, and the trend of drought is the most significant in the deepest soil. The drought degree varied spatially. The most severe drought area was located in the southern part of the study area, mainly in Henan Province. While in the north part of the study area, there is a trend of wetting.

(3) The annual trend analysis of VCI showed that the vegetation condition was generally improved in North China.

(4) The correlation coefficient between the vegetation index and drought index was positive both on the annual scale and monthly scale in most of the study area. The response of VCI to SMAI in the grassland, shrub, woodland, and farmland was significantly different. The correlation coefficient of farmland was much lower than that of the other vegetation types because human factors or natural factors including land management, soil fertility, crop harvesting, and other effects will also affect the crop growth.

\section{Conflicts of Interest}

The authors declare that they have no conflicts of interest.

\section{Acknowledgments}

This paper was jointly supported by the National Key R\&D Program of China (2017YFC0406004). The authors also would like to thank Professor Richard P. Greene and Professor Bob Su who provided help.

\section{References}

[1] J. W. Xu, H. Ju, Q. Liu, and J. Y. Yang, "Variation of drought and regional response to climate change in Huang-Huai-Hai plain," Acta Ecologica Sinica, vol. 34, no. 2, pp. 460-470, 2014, in Chinese.

[2] L. Wang and W. Chen, "A CMIP5 multimodel projection of future temperature, precipitation, and climatological drought in China," International Journal of Climatology, vol. 34, no. 6, pp. 2059-2078, 2014.

[3] Z. Su, Y. He, X. Dong, and L. Wang, "Drought monitoring and assessment using remote sensing," in Remote Sensing of Hydrological Extremes: Springer Remote Sensing/Photogrammetry, V. Lakshmi, Eds., pp. 151-172, Springer, Cham, Berlin, Germany, 2017.

[4] W. P. Yuan and G. S. Zhou, "Comparison between standardized precipitation index and Z-index in China," Journal of Plant Ecology, vol. 28, no. 4, pp. 523-529, 2004, in Chinese.

[5] T. B. Mckee, N. J. Doesken, and J. Kleist, "The relationship of drought frequency and duration to time scales," in Proceedings of the 8th Conference on Applied Climatology, vol. 1, pp. 17-22, Anaheim, CA, USA, January 1993.

[6] W. C. Palmer, Meteorological Drought, in Research Paper No. 45, U.S. Department of Commerce, Weather Bureau, Washington, DC, USA, 1965.
[7] S. M. Vicente-Serrano, S. Beguería, and J. I. López-Moreno, "A multiscalar drought index sensitive to global warming: the standardized precipitation evapotranspiration index," Journal of Climate, vol. 23, no. 7, pp. 1696-1718, 2010.

[8] N. Cong, S. Piao, A. Chen et al., "Spring vegetation green-up date in China inferred from SPOT NDVI data: a multiple model analysis," Agricultural and Forest Meteorology, vol. 165, pp. 104-113, 2012.

[9] D. Wu, X. Zhao, S. Liang et al., "Time-lag effects of global vegetation responses to climate change," Global Change Biology, vol. 21, no. 9, pp. 3520-3531, 2015.

[10] P. Camberlin, N. Martiny, N. Philippon, and Y. Richard, "Determinants of the interannual relationships between remote sensed photosynthetic activity and rainfall in tropical Africa," Remote Sensing of Environment, vol. 106, no. 2, pp. 199-216, 2007.

[11] X. Zhao, H. Wei, S. Liang et al., "Responses of natural vegetation to different stages of extreme drought during 20092010 in southwestern China," Remote Sensing, vol. 7, no. 10, pp. 14039-14054, 2015.

[12] V. Potopová, P. Štěpánek, M. Možný, L. Türkott, and J. Soukup, "Performance of the standardised precipitation evapotranspiration index at various lags for agricultural drought risk assessment in the Czech Republic," Agricultural and Forest Meteorology, vol. 202, pp. 26-38, 2015.

[13] Y. Q. Liu, "Impacts of vegetation on drought trends," Chinese Journal of Atmospheric Sciences, vol. 40, no. 1, pp. 142-156, 2016, in Chinese.

[14] B. Narasimhan and R. Srinivasan, "Development and evaluation of Soil Moisture Deficit Index (SMDI) and Evapotranspiration Deficit Index (ETDI) for agricultural drought monitoring," Agricultural and Forest Meteorology, vol. 133, no. 1-4, pp. 69-88, 2005.

[15] S. J. Chen, X. D. Guan, J. P. Huang, and M. X. Ji, “Analysis of response of soil moisture to climate change in semi-arid Loess Plateau in China based on GLDAS data," Journal of Arid Meteorology, vol. 31, no. 4, pp. 641-649, 2013, in Chinese.

[16] S. M. Vicente-Serrano, C. Gouveia, J. J. Camarero et al., "Response of vegetation to drought time-scales across global land biomes," Proceedings of the National Academy of Sciences, vol. 110, no. 1, pp. 52-57, 2013.

[17] S. K. Jain, R. Keshri, A. Goswami, and A. Sarkar, "Application of meteorological and vegetation indices for evaluation of drought impact: a case study for Rajasthan, India," Natural Hazards, vol. 54, no. 3, pp. 643-656, 2010.

[18] S. Y. Yang, Temporal and Spatial Variation of Drought and Vegetation Response in North China, Capital Normal University, Beijing, China, 2017, in Chinese.

[19] M. X. Li and Z. G. Ma, "Soil moisture drought detection and multi-temporal variability across China," Science China Earth Sciences, vol. 58, no. 10, pp. 1798-1813, 2015, in Chinese.

[20] S. J. Cheng, J. P. Huang, M. X. Ji, X. D. Guan, and R. X. Guo, "Variation feature of soil moisture in warm season over North China," Journal of Arid Meteorology, vol. 33, no. 5, pp. 723731, 2015, in Chinese.

[21] S. W. Zhuang, H. C. Zuo, P. C. Ren et al., "Application of standardized precipitation evapotranspiration index in China," Climatic and Environmental Research, vol. 18, no. 5, pp. 617-625, 2013, in Chinese.

[22] D. Zhou, Spatio-Temporal Changes and the Cause Analysis of Meteorological Drought in North China from 1961 to 2013, Northwest Normal University, Lanzhou, China, 2015, in Chinese. 
[23] N. Guo and X. P. Wang, "Advances and developing opportunities in remote sensing of drought," Journal of Arid Meteorology, vol. 33, no. 1, pp. 1-18, 2015, in Chinese.

[24] K. Xu, D. Yang, H. Yang, Z. Li, Y. Qin, and Y. Shen, "Spatiotemporal variation of drought in China during 1961-2012: a climatic perspective," Journal of Hydrology, vol. 526, pp. 253-264, 2015. 

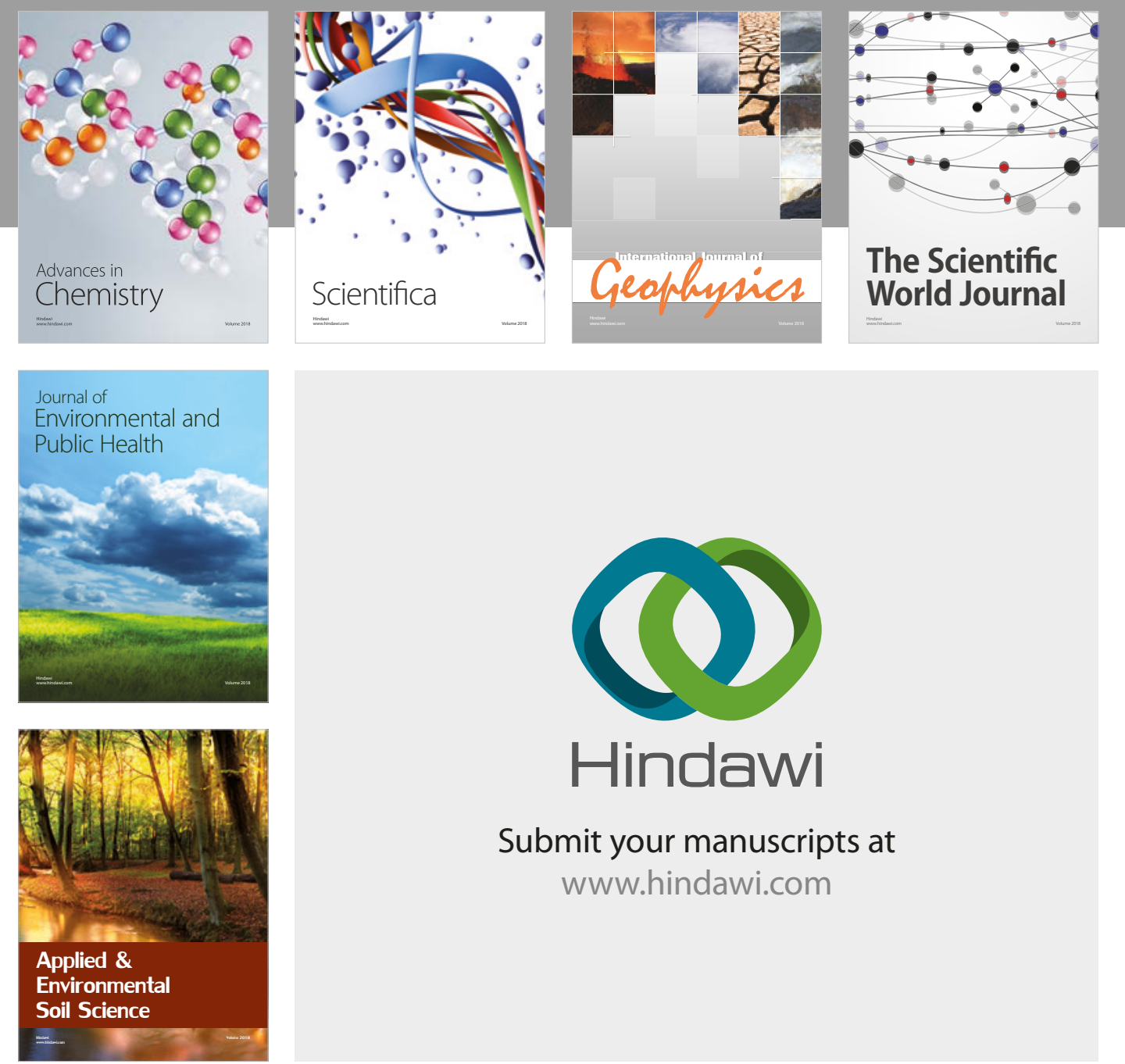

The Scientific

\section{World Journal}
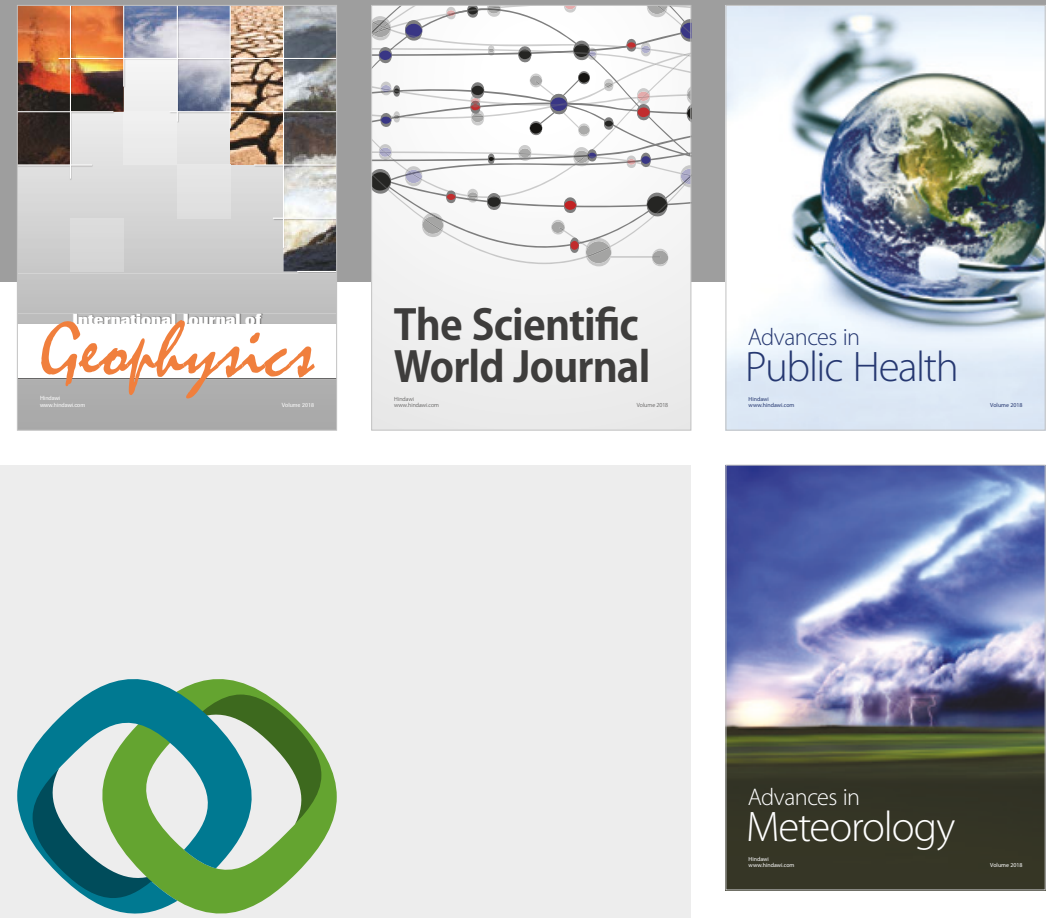

Advan

Public Health

\section{Hindawi}

Submit your manuscripts at

www.hindawi.com
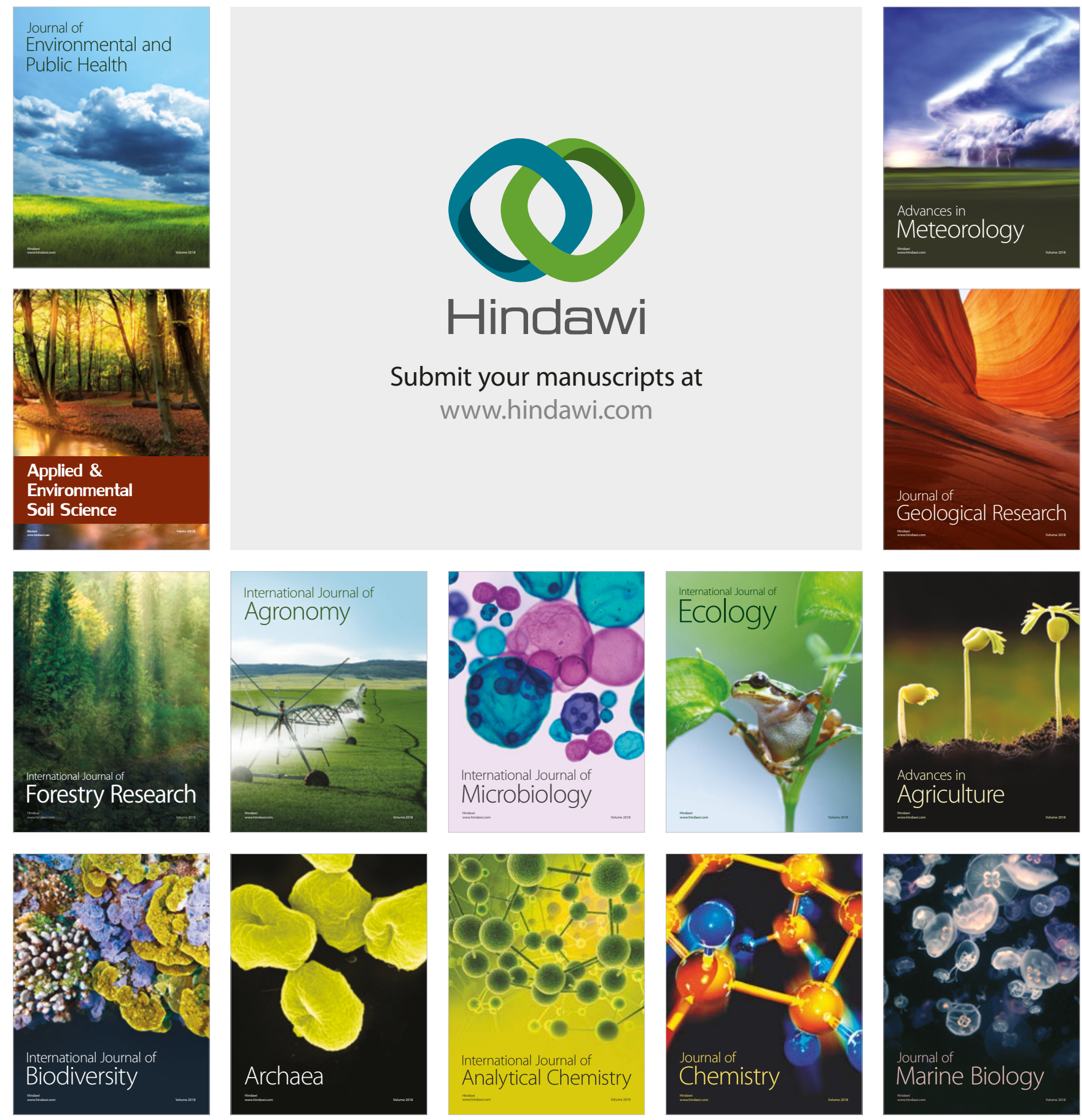